\title{
Medicina popular: benefícios e malefícios das plantas medicinais
}

\author{
Popular medicine: benefits and drawbacks of medicinal plants
}

Medicina popular: benefícios y malefícios de las plantas medicinales

\section{Inácia Sátiro Xavier de França', Jeová Alves de Souza', Rosilene Santos Baptista', Virgínia Rossana de Sousa Britto' \\ 'Universidade Estadual da Paraíba, Departamento de Enfermagem. Campina Grande, PB}

Submissão: 09/08/2007

Aprovação: 03/1 1/2007

\section{RESUMO}

Estudo descritivo objetivando verificar se os herbolários oferecem as informações corretas para a utilização das plantas medicinais; se orientam os clientes acerca das possíveis intoxicações ou interação com os alopáticos; e se utilizam critérios para a comercialização dos fitoterápicos. Utilizou-se um Questionário contendo Questões abertas e fechadas envolvendo aspectos da atuação dos herbolários com os fitoterápicos. Os herbolários conhecem a maioria das plantas medicinais, entretanto, há lacunas acerca da indicação correta desses produtos, dos efeitos colaterais e toxicidade. Os herbolários carecem conhecer melhor os princípios ativos das ervas, as indicações terapêuticas, orientar os usuários acerca das possíveis interações farmacológicas ou intoxicações medicamentosas e a respeito da limpeza, armazenamento, tempo de vida útil e contra-indicações do produto.

Descritores: Fitoterapia; Plantas medicinais; Medicina tradicional.

\section{ABSTRACT}

Descriptive study which aims to verify if the herbalist offer the information correct for the use of the medicinal plants; if they give for the customers concerning the possible poisonings or interaction with the allopathic guide and also if there is a criteria for the commercialization of the phytotherapics. A questionnaire was used containing open and closed Questions involving aspects of the performance of the herbalists with the phytotherapics. The herbalists know the majority of the medicinal plants, however, there are some gaps concerning the correct indication of these products, of the collateral effect and toxicities. The herbalist lack to better know the principles of the grass, the therapeutically indications active, to guide the users concerning the possible pharmacological interactions or medicaments poisonings and regarding the cleanness, storage, time of useful life and contraindications of the product.

Descriptors: Phytotherapy; Plants, medicinal; Medicine, tradicional.

\section{RESUMEN}

Estudio descriptivo con los objetivos de verificar se los herbolarios ofrecen las informaciones correctas para la utilización de las plantas medicinales; se orientan los clientes acerca de las posibles intoxicaciones o interaciones con los alopáticos y se utilizan critérios para la comercialización de los fitoterápicos. Se utilizó una encuesta conteniendo preguntas subjetivas y también objetivas tratando de aspectos de la actuación de los herbolarios con los fitoterápicos. Los herbolarios conocen la mayoría de las plantas medicinales, por lo tanto, hay huecos acerca de la indicación correcta de esos productos, de los efectos colaterales y de la toxicidad. Esos profesionales carecen conocer mejor los princípios activos de las hierbas, las indicaciones terapeuticas, orientar los usuários sobre las posibles interacciones farmacológicas o intoxicaciones medicamentosas y a respeto de puntos como limpieza, armazenamiento, tiempo de vida útil y contra-indicaciones del producto.

Descriptores: Fitoterapia; Plantas medicinales; Medicina tradicional. 


\section{INTRODUÇÃO}

O uso de remédios à base de ervas remonta às tribos primitivas em Que as mulheres se encarregavam de extrair das plantas os princípios ativos para utilizá-los na cura das doenças. À medida Que os povos dessa época se tornaram mais habilitadas em suprir as suas necessidades de sobrevivência, estabeleceram-se papéis sociais específicos para os membros da comunidade em Que viviam. $\mathrm{O}$ primeiro desses papéis foi o de curandeiro. Esse personagem desenvolveu um repertório de substancias secretas que guardava com zelo, transmitindo-o, seletivamente, a iniciados bem preparados ${ }^{(1)}$.

Os primeiros registros fitoterápicos datam do período 28382698 a.C. Quando o imperador chinês Shen Nung catalogou 365 ervas medicinais e venenos Que eram usados sob inspiração taoísta de Pan Ku, considerado deus da criação. Esse primeiro herbário dependia da ordenação de dois pólos opostos: yang - luz, céu, calor, esquerdo; e o yin - trevas, terra, frio, direito. Por volta de 1500 a C. a base da medicina hindu já estava revelada em dois textos sagrados: Veda (Aprendizado) e Ayurveda (Aprendizado de Longa Vida) ${ }^{(1,2)}$

No século XIX o empirismo da alquimia foi suplantado pela Química experimental Que permitiu a síntese laboratorial de novas substâncias orgânicas. Esse fato foi um dos fatores determinantes da revolução industrial e tecnológica Que desencadeou a produção acelerada de novos medicamentos e à medida Que derivados mais puros e concentrados de plantas se tornaram disponíveis os médicos priorizaram as drogas sintéticas e passaram a desconsiderar o papel importante da fitoterapia ${ }^{(1,3)}$.

$\mathrm{O}$ advento da medicina científica contribuiu para o aumento da sobrevida humana. E, no cotidiano das práticas de saúde, a aplicação de princípios científicos desencadeou a descoberta de terapêuticas Que melhoraram a Qualidade de vida das pessoas. Esse avanço da ciência fez com Que o paradigma cartesiano passasse a ser adotado para explicar o processo saúde-doença. Contudo, desde o século XX, esse paradigma vem cedendo espaço ao paradigma holístico graças às teorias de Einstein. Para esse cientista a matéria é uma manifestação de energia. Os seres humanos são formados de matéria e os seus vários sistemas energéticos interagem entre si e com o meio, formando um todo Que deve sempre estar harmonizado. $\mathrm{O}$ todo só estará harmônico se o complexo mente-corpo-meio ambiente estiver em equilíbrio ${ }^{(4,5)}$.

A fitoterapia permite Que o ser humano se reconecte com o ambiente, acessando o poder da natureza, para ajudar o organismo a normalizar funções fisiológicas prejudicadas restaurar a imunidade enfraquecida, promover a desintoxicação e o rejuvenescimento.

Médicos e pacientes nem sempre conseguem literatura adeeuada para avaliar devidamente as vantagens e os riscos desta prática terapêutica, sobretudo Quando seu maior emprego é estimulado por práticas médicas não convencionais, como Medicina chinesa, Medicina holística, terapêutica médica indiana, macrobiótica, entre outras. As pessoas costumam utilizar os produtos do reino vegetal, seja como complemento alimentar, suplementos energéticos ou vitamínicos, baseando-se nas informações da mídia. Em se tratando do processo saúde-doença, a fitoterapia é amplamente utilizada pela população campesina, mas nos meios industrializados Quem a utiliza costuma fazê-lo de forma velada para não se expor às atitudes críticas dado Que esse tipo de medicina submete-se ao controle da medicina oficial( ${ }^{(6)}$.

Estudos sobre a medicina popular vêm merecendo atenção cada vez maior devido ao contingente de informações e esclarecimentos Que vem sendo oferecido à Ciência. Esse fenômeno tem propiciado o uso de chás, decoctos, tisanas e tinturas fazendo com Que, na maioria dos países ocidentais, os medicamentos de origem vegetal sejam retomados de maneira sistemática e crescente na profilaxia e tratamento das doenças, ao lado da terapêutica convencional ${ }^{(2)}$.

Percebe-se, na atualidade, o interesse governamental e profissional em associar o avanço tecnológico ao conhecimento popular e ao desenvolvimento sustentável visando a uma política de assistência em saúde eficaz, abrangente, humanizada e independente da tecnologia farmacêutica. Nesse sentido, o Estado brasileiro instituiu a Portaria no22/1967 da Agência Nacional de Vigilância Sanitária e a Resolução-RDC no 17/2000 Que classifica os fitoterápicos como medicamentos ${ }^{(7)}$.

Paralelo ao interesse governamental em debater a comercialização dos fitoterápicos, a adesão da população a esses produtos incrementou a sua comercialização de modo Que o Estado precisou regulamentar esse mercado editando a Resolução RDC no 17/00, Que estabelece os parâmetros de Qualidade para o registro desses produtos junto ao Ministério da Saúde ${ }^{(7)}$.

Ao tomar por base Que o uso de fitoterápicos é uma prática utilizada por alguns profissionais da saúde. Que esses profissionais, também associam o uso dos alopáticos com o de fitoterápicos. E Que a população utiliza-se dos fitoterápicos respaldando-se na tradição cultural, pergunta-se: existe a possibilidade de os fitoterápicos interagirem com os medicamentos alopáticos modificando ou anulando a ação terapêutica de um ou de ambos? Os herbolários tradicionais ensinam, corretamente, aos usuários, como armazenar e utilizar as plantas medicinais? Eles mencionam, corretamente, as indicações e contra-indicações das plantas?

Considere-se, ainda, eue os profissionais de Enfermagem atuam nos programas de saúde onde exercitam a Consulta de Enfermagem, momento em Que podem orientar os usuários interessados em utilizar a medicina natural. Como esse conhecimento costuma ser obtido, com maior freqüência, pela tradição oral, a sua indicação profissional precisa estar respaldada em bases científicas.

Face ao exposto, essa investigação pretendeu alcançar os seguintes objetivos: verificar se os herbolários atuantes na cidade de Campina Grande-PB oferecem as informações necessárias à utilização correta das plantas medicinais; se orientam os clientes acerca da possibilidade de intoxicação ou de interação com os alopáticos; e se utilizam critérios para a comercialização dos fitoterápicos.

\section{METODOLOGIA}

Trata-se de um estudo exploratório, descritivo e de campo realizado no mercado informal de plantas medicinais de Campina Grande-PB, no período de agosto de 2006 a junho de 2007. sobre o uso de medicamentos e/ou fitoterápicos

O projeto foi aprovado no Comitê de Ética em Pesquisa da Universidade Estadual da Paraíba (UEPB), sob o $\mathrm{N}^{\circ}$ 0 144.0.133.000.06, em 21 de junho de 2006. A população foi composta por todos os vendedores de partes de plantas medicinais 
atuantes na zona urbana de Campina Grande-PB. A amostra foi composta por acessibilidade perfazendo um total de 14 herbolários Que aceitaram participar da pesquisa, após terem sido esclarecidos acerca dos objetivos, dos riscos e benefícios do estudo, e de terem assegurado o direito ao sigilo e a retirar-se da pesquisa em Qualeuer momento, sem QualQuer tipo de prejuízo, conforme estabelece a Resolução 196/96 do Conselho Nacional de Saúde.

O instrumento de coleta foi um Questionário contendo Questões abertas e fechadas sobre dados sociodemográficos, origem do conhecimento sobre fitoterapia, tempo de atuação como herbolário, procedência das ervas, conhecimento sobre as principais doenças e o respectivo fitoterápico indicado para tratamento, efeitos indesejados dos fitoterápicos e critérios de comercialização.

Quando da análise, os dados sociodemográficos foram tratados através da estatística descritiva; os dados pertinentes ao conhecimento dos herbolários sobre as doenças e o respectivo tratamento fitoterápico foram padronizados e disposto em Quadros demonstrativos. Os demais dados foram padronizados e categorizados tematicamente $\mathrm{e}^{(8)}$.

\section{RESULTADOS DISCUSSÃO}

\section{Dados Sociodemográficos}

Detectou-se Que $57 \%$ dos herbolários é do sexo feminino e $43 \%$ do sexo masculino. Essas pessoas situam-se em uma faixa etária da seguinte ordem: $14,28 \%$, de 20 a 29 anos; $14,28 \%$, de 30 a 39 anos; $14,28 \%$, de 40 a 49 anos; $42,89 \%$, de 50 a 59 anos; e $14,28 \%$ de 60 a 69 anos, dados Que confirmam a tradição oral no uso da fitoterapia.

Em relação ao estado civil, identificou-se $28,57 \%$ de homens solteiros; $28,57 \%$ de mulheres solteiras; $28,57 \%$ de mulheres casadas, e 14,28\% de homens casados.

A distribuição dos participantes, segundo a cidade de origem indicou Que 57, 13\% residem em Campina Grande-PB e 42,87\% procedem de cidades circunvizinhas. A diversidade da procedência dos herbolários possibilita a inferência Que essas pessoas possuem conhecimentos variados sobre plantas medicinais, devido à diversidade biológica encontrada em cada uma das regiões da Paraíba.

Apesar de 42,87\% dos herbolários não residirem em Campina Grande, eles comercializam os fitoterápicos nesse município devido a facilidade de deslocamento e o acesso Que têm aos agricultores Que colhem, selecionam, acondicionam e transportam a matéria vegetal para o Mercado Central de Campina Grande-PB.

No concernente a escolaridade, detectou-se Que todos os herbolários têm, em média, três anos de estudo. E, em se tratando da religião, identificou-se 78,57\% de católicos; 14,28\% de evangélicos e 7,14\% Que afirmaram não ter religião.

\section{A origem do conhecimento sobre fitoterapia}

Os resultados dão conta Que 21,42\% aprenderam a usar os fitoterápicos no convívio do dia-dia com amigos; 7, 14\% aprendeu com parentes; $57,13 \%$ adeuiriram esse conhecimento com os pais; $7,14 \%$ aprendeu ajudando pessoas mais antigas a prepararem e venderem as ervas e 7,14\% aprendeu sozinho, com a prática cotidiana das vendas de plantas nos locais de trabalho.

Entre todas as pessoas Que foram entrevistadas, apenas uma, relatou Que além dos conhecimentos sobre as plantas medicinais Que adeuiriu com os pais, sempre procura ler livros Que falam sobre o tratamento com preparo de ervas e que procura transmitir esse conhecimento aos clientes a Quem vende seus produtos.

\section{Tempo de atuação como herbolário}

Na zona urbana de Campina Grande, foram identificados 21 , 42\% de homens e 7, $14 \%$ de mulheres herbolários com atividade entre um a dez anos; $21,42 \%$ de homens e $21,42 \%$ de mulheres, entre 11 a 20 anos; e 28,56\% de mulheres com mais de 25 anos de atividade.

O predomínio das mulheres na prática fitoterápica mantém relação, também, com a divisão social de trabalho instituída na atualidade o que desencadeou mudanças nos papéis de gênero, de modo Que o desemprego dos homens obriga as mulheres ao trabalho fora de casa em benefício da sobrevivência do núcleo familiar. A figura histórica do curandeiro, conhecido popularmente nas feiras livres por herbolário, herbário ou raizeiro tem resistido ao tempo e às inovações da medicina científica, perdurando até os dias atuais e sendo muito procurados pela população para a aQuisição de ervas medicinais, partes destas ou produtos já confeccionados e direcionados ao tratamento de problemas de saúde.

\section{A procedência das ervas}

O percentual $79 \%$ dos herbolários refere-se àqueles Que adeuirem as ervas em armazéns especializados nesses produtos ou com intermediários Que as trazem da roça. O percentual $21 \%$ é relativo àQueles que cultivam e colhem as ervas diretamente de seus jardins e as trazem para a feira.

Os herbolários vendem sementes, folhas, cascas e raízes de plantas medicinais. Os grandes volumes desses produtos são acondicionados em sacos e pacotes, reservando-se pequenos volumes Que são expostos ao público conforme a nomenclatura popular. Nos balcões de venda não se encontram, facilmente, partes frescas de plantas, como folhas, flores e galhos. Observou-se Que alguns produtos estavam em degradação ou atacados pelo mofo e, mesmo assim, eram comercializados. A ingestão, mesmo na forma de chá, desses produtos contaminados com micotoxinas pode ocasionar intoxicações agudas ou crônicas, pois esses microrganismos são termoestáveis ${ }^{(9)}$.

A Organização Mundial da Saúde(OMS) considera Que o limite máximo permitido para a carga de fungos filamentosos é de $5 \times 10^{2}$ UFC/g. Relatos da literatura enfocam a susceptibilidade dos fitoterápicos à contaminação fúngica durante o processo de plantio e colheita. E de contaminação secundária durante a manipulação e o armazenamento inadequado destes produtos ${ }^{(10)}$. Mesmo os chás e ervas vendidos em farmácias podem ser fonte de intoxicação por vírus, bactérias e fungos contaminantes, pois não existem estudos de segurança, eficácia e Qualidade de grande parte das plantas ${ }^{(1)}$. E Que as colheitas mal elaboradas e secagens inadeQuadas podem contribuir para o rápido aparecimento de produtos de decomposição no vegetal; prosseguindo-se conseQüentemente a perda total ou em parte dos princípios ativos existentes na planta ${ }^{(12)}$.

\section{Conhecimento dos herbolários sobre as doenças e indicações fitoterápicas \\ O ônus elevado da assistência médica privada, a precariedade}


da assistência prestada pelos serviços públicos e o alto custo dos alopáticos vem motivando, em todo o mundo, uma maior adesão ao uso da medicina natural. Estima-se que existam aproximadamente 500 mil espécies de plantas no mundo. Dessas, o Brasil possui 120 mil, tomando a posição de país com a maior cobertura vegetal do globo terrestre ${ }^{(13)}$ Assim, uma Questão a ser considerada é a crescente utilização de plantas medicinais e fitoterápicos como componentes alternativos ou mesmo complementares da terapêutica medicamentosa.

A Organização Mundial de Saúde apóia a fitoterapia por considerá-la uma prática da medicina tradicional ${ }^{(1)}$ Entretanto, o seu uso reQuer a identificação e a classificação botânica correta, para evitar de induzir os usuários ao erro devido ao princípio ativo variar de planta a planta em função da biodiversidade, código genético, condições climáticas, mudanças sazonais, índice pluviométrico, luminosidade, lençol freático, condições do solo, dentre outras condições ${ }^{(2)}$.

O conhecimento das propriedades medicinais da maioria das plantas é comum aos herbolários. Mas, comparando-se os Quadros I e 2, verificou-se Que algumas indicações feitas pelos herbolários não se confirmaram na literatura. Logo, a identificação botânica, pelo herbolário, é passível de incorreção, pois um mesmo nome popular pode incluir várias espécies botânicas, ou uma mesma espécie pode apresentar várias denominações populares.

\begin{tabular}{|c|c|c|c|}
\hline \multicolumn{2}{|c|}{ DOENÇAS } & \multicolumn{2}{|c|}{ PLANTA MEDICINAL INDICADA } \\
\hline Nome popular & Nome Cientifico & Nome popular & Nome Científico \\
\hline Anemia & Anemia & Tomate ( - ) & Solanum lycopersicum \\
\hline Broneuite & Broneuite & Hortelã da folha grossa ( - ) & Plectranthus ambuinicus lour \\
\hline Cansaço & Asma & $\begin{array}{l}\text { Cebola-branca ( - ) } \\
\text { Mangará de bananeira ( - ) }\end{array}$ & $\begin{array}{l}\text { Allium ascalonicum L; } \\
\text { Musa spp }\end{array}$ \\
\hline Catarro no peito & Tosse produtiva & $\begin{array}{l}\text { Cebola-branca }(+) \\
\text { Limão }(+)\end{array}$ & $\begin{array}{l}\text { Allium ascalonicum L.; } \\
\text { Citrus Limonum Risso; }\end{array}$ \\
\hline Coceira & Escabiose & Bálsamo ( - ) & Myroxylon toluifera; \\
\hline Cólica & Cólica abdominal & $\begin{array}{l}\text { Chá preto }(+) \\
\text { Capitãozinho (-) }\end{array}$ & $\begin{array}{l}\text { Tea sinensis linn; } \\
\text { Gomphrena demissa }\end{array}$ \\
\hline Diarréia & Diarréia & $\begin{array}{l}\text { Malva-rosa }(-) \\
\text { Chá preto }(+) \\
\text { Sena }(-)\end{array}$ & $\begin{array}{l}\text { Malva silvestris; } \\
\text { Tea sinensis Linn; } \\
\text { Cassia angustifólia }\end{array}$ \\
\hline Febre & Hipertermia & $\begin{array}{l}\text { Eucalipto }(+) \\
\text { Flor-de-sabugueiro }(+)\end{array}$ & $\begin{array}{l}\text { Eucalyptus globulos Labill, } \\
\text { Sambucus nigra }\end{array}$ \\
\hline Feridas & úlceras & Favela $(+)$ & Cnidoscolus phyllacanthus \\
\hline Gripe & Gripe & $\begin{array}{l}\text { Acerola }(+) \\
\text { Mastruz }(+) \\
\text { Cebola-branca }(-)\end{array}$ & $\begin{array}{l}\text { Malpighia emarginata; } \\
\text { Chenopodium ambrosioides; Allium } \\
\text { ascalonicum L. }\end{array}$ \\
\hline $\begin{array}{l}\text { Inflamação da } \\
\text { garganta }\end{array}$ & Faringite/Laringite & $\begin{array}{l}\text { Cebola-branca ( - ) } \\
\text { Romã }(+)\end{array}$ & $\begin{array}{l}\text { Allium ascalonicum L.; } \\
\text { Punica granatum }\end{array}$ \\
\hline Reima de dentes & $\begin{array}{l}\text { Erupção da primeira } \\
\text { dentição }\end{array}$ & Pepaconha $(+)$ & Cephaelis ipepacuanha \\
\hline Pneumonia & Pneumonia & $\begin{array}{l}\text { Limão ( + ) } \\
\text { Hortelã da folha grossa ( - ) }\end{array}$ & $\begin{array}{l}\text { Citrus Limonum Risso; } \\
\text { Plectranthus ambuinicus lour }\end{array}$ \\
\hline Problemas de rins & Litíase/Nefrite, etc & Urinana (?) & Zornia Diphilla Pers. \\
\hline Resfriado & Resfriado & Hortelã da folha grossa ( - ) & Plectranthus ambuinicus lour \\
\hline Umbigo inflamado & Infecção Umbilical & Cajueiro roxo $(+)$ & Anacardium occidentale \\
\hline Vermes & Verminoses & Batata-de-purga ( - ) & Operculina hamiltonii \\
\hline
\end{tabular}

Quadro 1. Correlação entre a nomenclatura das doenças e a indicação fitoterápica segundo o saber popular e o saber científico. Campina Grande- PB, 2007. 
Medicina popular: benefícios e malefícios das plantas medicinais

\begin{tabular}{|c|c|c|c|}
\hline \multicolumn{2}{|c|}{ PLANTA MEDICINAL INDICADA } & \multicolumn{2}{|c|}{ CONHECIMENTO CIENTÍFCO } \\
\hline Nome popular & Nome científico & Tratamento de: & Planta/partes \\
\hline Acerola & Malpighia emarginata & Afecções pulmonares & Frutos \\
\hline Bálsamo & Myroxylon toluifera & Tosse bronQuite & Resina \\
\hline Bananeira & Musa spp & Cicatrizante & Inflorescência \\
\hline Batata-de-purga & Operculina hamiltonii & $\begin{array}{l}\text { Afecções por moluscos } \\
\text { (esQuistosomose) }\end{array}$ & Tubérculo \\
\hline Cajueiro & Anacardium occidentale & $\begin{array}{l}\text { Ação antimicrobiana e } \\
\text { hipoglicemiante }\end{array}$ & Casca \\
\hline Capitãozinho & Gomphrena demissa & Atividade estrogênica & Raízes \\
\hline Cebola-branca & Allium ascalonicum $L$. & Tosse produtiva & Bulbo \\
\hline Chá preto & Tea sinensis linn & Diarréias & Folhas ou botões florais \\
\hline Eucalipto & Eucalyptus globulos Labill & Bronquite e antitérmico & Folhas \\
\hline Favela & Cnidoscolus phyllacanthus & Infecções (atividade citotóxica) & Casca e entr ecasca \\
\hline Hortelã da folha grossa & Plectranthus ambuinicus lour & Cefaléia, cólica & Folhas \\
\hline Limão & Citrus Limonum Risso & Gripe e pneumonia & Fruto \\
\hline Malva-rosa & Malva silvestris & Bronquite, constipação & Folhas \\
\hline Mastruz & Chenopodium ambrosioides. & $\begin{array}{l}\text { Afecções pulmonares e das vias } \\
\text { aérias }\end{array}$ & $\begin{array}{l}\text { Folhas e sumidades } \\
\text { florais }\end{array}$ \\
\hline Pepaconha & Cephaelis ipepacuanha & Vermífugo & Raízes \\
\hline Romã & Punica granatum & Faringite, diarréia e hemorróidas & Fruto \\
\hline Sabugueiro & Sambucus nigra & Laringite e febre & Flores \\
\hline Sena & Cássia angustifólia & Cólicas e diarréia & Folhas \\
\hline Tomate & Solanum lycopersicum & Constipação e úlceras de pele & Folhas e frutos \\
\hline Urinana & Zornia Diphilla Pers. & $\begin{array}{l}\text { Não encontrado na literatura } \\
\text { consultada }\end{array}$ & - - \\
\hline
\end{tabular}

Quadro 2. Plantas medicinais indicadas pelos herbolários para tratamento das doenças e sua utilização, segundo a literatura consultada.

Outrossim, há a dificuldade em excluir o efeito placebo na avaliação da eficácia dos fitoterápicos, dado Que esse efeito é inerente ao contexto sociocultural em Que se inserem as várias camadas populares $^{(14)}$.

\section{Precauções no uso dos fitoterápicos}

As comunidades nordestinas usam, comumente, o termo resguardo para advertir as puérperas acerca de repouso absoluto durante 15 dias, não lavar a cabeça, não comer alimentos Quentes ou frios, não fazer esforços físicos ${ }^{(15)}$ abster-se de carne suína, peixes e ovos, frutas ácidas repolho, couve-flor, abóbora e mandioca ${ }^{(16)}$. Mas, o resguardo também se aplica a determinados cuidados na convalescença de uma doença ou de um procedimento cirúrgico.

Interrogou-se os herbolários acerca da indicação, ou não, de resguardo para os clientes em uso de ervas medicinais. Detectouse $57,13 \%$ dos herbolários recomendam resguardo; e 42,87\% não o recomendam, pois acreditam Que as plantas medicinais não fazem mal algum a saúde das pessoas.

Perguntou-se aos herbolários se havia plantas medicinais capazes de intoxicar o doente. Dentre os entrevistados, 50\% reafirmou a inocuidade dos fitoterápicos, e 50\% afirmaram haver várias plantas Que são tóxicas.

Em estudos anteriores foi observado Que fitoterápicos colhidos de regiões diferentes, apresentam variabilidade do efeito terapêutico da mesma planta devido à variedade Química dos $\operatorname{solos}^{(17)} \mathrm{E}$ Que a composição dos princípios ativos das plantas é variável em decorrência das diferentes condições de cultivo, colheita, secagem, armazenamento e preparo dos fitoterápicos ${ }^{(14)}$.

Em muitos casos as pessoas subestimam as propriedades medicinais das plantas e fazem uso delas de forma aleatória. Entretanto, cada vegetal, em sua essência, pode ser alimento, veneno ou medicamento. A distinção entre as substâncias alimentícias, tóxicas e medicamentosas se faz apenas com relação à dose, a via de administração e a finalidade com Que são empregadas $^{(18)}$. 
Um fitoterápico é, freQüentemente, composto por mais de uma espécie Química. Quando padronizado como "medicamento fitoterápico" deveria estar submetido às mesmas exigências de identificação, pureza, teor e aos demais estudos farmacopéicos Que os medicamentos industrializados obtidos por síntese ou processos biotecnológicos, além de testes clínicos e pré-clínicos, antes de sua comercialização. No entanto, nem sempre essas exigências são observadas. Nesta situação é difícil estimar exatamente Quais princípios ativos estarão presentes e em Que concentração ${ }^{(17)}$.

Há uma tendência a generalização do uso de plantas medicinais por se entender que tudo Que é natural não é tóxico nem faz mal a saúde. Este conceito é errôneo, porQue existe uma imensa variedade de plantas medicinais Que, dentre outras propriedades prejudiciais ao organismo humano, são providas de grande teor de toxicidade pela presença de constituintes farmacologicamente ativos, por conseguinte muito tóxicos ${ }^{(17)}$.

Alguns autores desaconselham o uso de plantas medicinais ou de partes destas, concomitantes com o uso de medicações alopáticas $^{(19)}$. Por se constituírem produtos xenobióticos, os fitoterápicos empregados no período pré-operatório podem afetar o ato anestésico ao interagir com os agentes anestésicos, tanto na fase farmacocinética, como na farmacodinâmica ${ }^{(20)}$.

Em um relato de pesquisa detectou-se Que o ginko biloba, alho em comprimido, ginseng e gengibre alteram a coagulação sanguínea. Para os autores, em caso de cirurgia, é preciso investigar previamente o uso dessas drogas e, se afirmativo, suspender até o $10^{\circ}$ dia de pré-operatório, com o objetivo de reduzir as eventuais complicações hemorrágicas no pré e pós-operatórias, prevenindo possíveis implicações médicas e legais ${ }^{(21)}$. Em outro relato, o boldo é citado como um poderoso analgésico capaz de mascarar sintomas de uma enfermidade grave. Não se pode descartar a possibilidade de efeitos colaterais dos fitoterápicos Quando se associam duzentas ou trezentas substâncias ao princípio ativo desejado. Também porQue a identificação taxonômica das plantas utilizadas pode ser duvidosa, ou porQue a dosagem é de difícil controle(22).

A União Européia tem incentivado estudos para a determinação dos efeitos tóxicos e adversos Que os fitoterápicos possam ter. Porém, as informações toxicológicas Que chegam aos países Ocidentais são muitas vezes reduzidas ${ }^{(17)}$. A Organização Mundial da Saúde(OMS) tem promovido reuniões internacionais no intuito de criar melhores condições de Qualidade, eficácia e segurança dos produtos fitoterápicos; havendo a pretensão de otimizar o seu uso nos países em desenvolvimento. Deste modo, a OMS tem se empenhado em elaborar diretivas convincentes a fim de dar maior garantia aos consumidores de produtos fitoterápicos ${ }^{(17)}$.

Por sua vez, o Ministério da Saúde (MS) tem encorajado o desenvolvimento de estudos com plantas tradicionais, com a esperança de obter os possíveis benefícios que as pesquisas sobre este assunto podem trazer. E objetiva evitar efeitos irracionais ou prejuízos Que esse tipo de medicina pode ocasionar ${ }^{(13)}$.

Em relação ao aconselhamento dos clientes a usarem as ervas e a consultarem um médico, obteve-se Que 35.7\% dos herbolários praticam essa orientação. E 74,3\% afirmam não haver tal necessidade, pois, “... Os médicos é Quem manda que as pessoas procurem os raizeiros para comprarem as ervas para o tratamento" (Júlio). "As ervas são produtos naturais e não fazem mal para ninguém" (Pedro). "As pessoas Que compram as ervas sabem Que os resultados são bons" (Cícera). "... As pessoas preferem se tratar com ervas porque sabem que as ervas curam” (Ana). "... As ervas têm um melhor efeito Que os medicamentos" (Lili).

A convicção dos herbolários em indicarem o uso de plantas medicinais não pode descartar a preocupação com possíveis efeitos indesejados desencadeados pelos fitoterápicos, Quando do uso inadecuado em dosagens ou mesmo o uso da planta errada para determinado tratamento. Nem a possibilidade da automedicação e subnotificado ao clínico. Diferentes interações têm sido descritas entre fitoterápicos e fármacos Quimicamente definidos e, algumas associadas à modulação da atividade enzimática no sítio de atuação $0^{(13)}$.

\section{Os critérios de comercialização dos fitoterápicos pelos herbolários}

Identificou-se Que 78,56\% dos herbolários não utilizam Quaisquer critérios para a comercialização dos fitoterápicos, vendendo-os para Qualeuer pessoa e receitando para idosos, adultos e crianças. E Que 21 ,47\% afirmaram vender as ervas para alguém da família do doente, a Quem orientam sobre como utilizá-las.

O uso de Qualquer terapêutica em idosos e criança requer maiores cuidados, pois os idosos estão em processo de degeneração orgânica, o Que de certa forma dificulta o curso dos princípios ativos das ervas ou medicamentos alopáticos no organismo e as crianças menores de um ano de idade possuem órgãos Que não alcançaram a total maturidade, como é o caso do fígado e dos rins. Estes órgãos são vitais e de fundamental importância para a manutenção do metabolismo, sendo responsáveis por desempenharem várias funções, dentre elas a de metabolização e eliminação de substâncias ${ }^{(23)}$.

Devido a essas particularidades das crianças e dos idosos, fazse necessário o entendimento, por parte do herbolário, sobre o tipo de erva a ser receitada, como utilizá-la e sobre a dosagem correta. Existe, pois, a necessidade de segurança, tanto por parte de Quem vende, como por parte de Quem compra e utiliza o fitoterápico.

\section{Implicações do uso de fitoterápicos para a enfermagem}

O Conselho Federal de Enfermagem (COFEN), atento à utilização de ervas medicinais na cultura popular e reconhecendo Que os enfermeiros precisam esclarecer e educar a clientela para o uso correto da fitoterapia, emitiu o Parecer Informativo 004/95, em Que reconhece o caráter holístico da formação do Enfermeiro e os aspectos ético-legais da utilização das práticas alternativas no cuidado ao cliente. Em seguida, essa entidade editou a Resolução 197/97, estabelecendo as Terapias Alternativas como especialidade do profissional de Enfermagem. Para atuar como terapeuta alternativo o enfermeiro precisa concluir, com aprovação, um curso de especialização nessa modalidade de tratamento. Esse curso precisa ser reconhecido em instituição de ensino, e ter carga horária mínima de 360 horas $^{(24)}$.

A medicina natural vem, de longa data, inspirando os profissionais de enfermagem. Antes mesmo do COFEn editar a Resolução 197/ 97 Que criou a Especialização em Terapias Alternativas, 47 enfermeiros brasileiros já atuavam utilizando as Terapias Alternativas no tratamento de seus pacientes ${ }^{(25)}$. 
A academia também reconheceu e valorizou a utilização de ervas medicinais na cultura popular, de modo que o componente curricular Fitoterapia vem sendo inserido no projeto Político pedagógico dos Cursos de Graduação em Enfermagem. Esse componente é abordado de forma obrigatória ou optativa durante a graduação. Entretanto, o conhecimento sobre as terapias alternativas não é, ainda, de domínio de todos os docentes, o Que pode restringir a formação dos alunos, uma vez Que todas as disciplinas da grade curricular estão envolvidas nesse processo ${ }^{(24)}$.

Relata-se que o conhecimento adQuirido pelos alunos acerca das terapias alternativas tem maior relação com o "saber popular", oriundos dos meios de comunicação e da tradição oral, do que com o "saber oficial". Assim, dentre os alunos, a terapia mais conhecida é a das essências florais, talvez porQue as instituições de ensino têm atuação específica nessa área ${ }^{(24)}$.

Ao considerar Que nem todos os profissionais têm conhecimento pleno da taxonomia do material botânico; Que os fitoterápicos encerram a possibilidade de efeitos colaterais e intoxicações, e Que as indicações, o preparo e a dosagem ideal desse produto não podem ser desconhecidos do enfermeiro que faz uso dessa terapia, entende-se Que as falhas na administração dos fitoterápicos, da mesma forma Que as falhas na preparação e administração dos medicamentos alopáticos, submetem-se aos postulados ético-legais.

Assim, a formação na área de saúde não pode ser reduzida às normas, regras ou padrões lineares, nem ao simples reordenamento de disciplinas e cargas horárias ${ }^{(25)}$. Entende-se que há necessidade de inclusão de um componente que enfoQue as práticas alternativas em todos os Projetos Político Pedagógicos dos Cursos de Graduação das escolas públicas e privadas.

\section{CONSIDERAÇÕES FINAIS}

A figura do herbolário alcançou importante papel econômico na sociedade devido a comercialização das plantas e difusão do conhecimento sobre seus efeitos de cura. E esse tipo de tratamento vem ganhando maior adesão da população e de alguns profissionais de saúde.

Os herbolários participantes desse estudo têm um bom conhecimento acerca do princípio ativo das ervas. Entretanto, percebeu-se lacunas no concernente a indicação correta dos fitoterápicos para o tratamento de alguma doença, fato sugestivo de Que esses profissionais carecem de capacitação para Que possam proceder a uma padronização correta dos fitoterápicos, correlacionar, com acerto, os princípios ativos das plantas com as indicações terapêuticas e orientar os usuários acerca das possibilidades de interações farmacológicas ou intoxicações medicamentosas.

Além das orientações disponibilizadas acerca da preparação do fitoterápico, é preciso que os herbolários orientem sobre a limpeza, armazenamento, tempo de vida útil das ervas e contra-indicações do produto, para minimizar a probabilidade de efeitos adversos ou de outros problemas de saúde, a exemplo da intoxicação.

No concernente ao Enfermeiro Que pratica a fitoterapia ou Que esteja inserido na saúde pública, espera-se Que desenvolva educação em saúde com a comunidade a fim de minimizar ou impedir a ocorrência de casos de intoxicação ou de outros agravos á saúde decorrentes do uso indevido das plantas medicinais.

\section{REFERÊNCIAS}

1. Simon D. O guia Decepar Chora de ervas: 40 receitas naturais para uma saúde perfeita. Rio de Janeiro(RI): Campus; 2001.

2. Vale NB. A farmacobotânica, ainda tem lugar na moderna anestesiologia? Rev Bras Anestesiol 2002; 52(3): 368-80.

3. Bratman S. Guia prático de medicina alternativa: Uma avaliação realista dos métodos alternativos de cura. Rio de Janeiro(Rl): Campus; 1998.

4. Gerber R. Medicina Vibracional: uma medicina para o futuro. São Paulo(SP): Cultrix; 1988.

5. Souza D, Silva MIP. O bucolismo espiritualista como referencial teórico para o enfermeiro. Rev Esc Enferm USP 1992; 26(2): 235-42.

6. Camargo MTLA. Medicina popular: aspectos metodológicos para pesquisa, garrafada, objeto de pesquisa, componentes medicinais de origem vegetal, animal e mineral. São Paulo(SP): ALMED; 1985.

7. Ministério da Saúde (BR). Agência Nacional de Vigilância Sanitária. Resolução RDC no 17 de 24 de fevereiro de 2000. Aprova o Regulamento técnico visando normatizar o registro de medicamentos fitoterápicos junto ao sistema de vigilância sanitária. Diário Oficial da União 25 Fev 2000; Seção 1: 25.

8. Bardin L. Análise de conteúdo. Lisboa (POR): Edições 70; 1977.

9. Araújo ALA, Ohara MT. Qualidade microbiológica de drogas vegetais comercializadas em feira de São Paulo e de infusos derivados. Rev Bras Cienc Farm 2000; 36(1): 129-37.
10. Souza TP, Lionzo MIZ, Petrovick PR. Avaliação da redução da carga microbiana de droga vegetal através do processamento tecnológico: decocção e secagem por aspersão. Rev Bras Farm 2006 Jan/Mar; I6(1): 94-8.

11. Rocha LO, Soares MMSR, Corrêa CL. Análise da contaminação fúngica em amostras de Cássia acutifólia Delile (sene) e Peumus boldus (Molina) Lyons (boldo-do-Chile) comercializadas na cidade de Campinas, Brasil. Rev Bras Cienc Farm 2004; 40 (4): $52 \mathrm{I}-7$

12. Panizza S. Ensinando a cuidar da saúde com as plantas medicinais: Guia prático de remédios simples da natureza. São Paulo (SP): Prestígio; 2005.

13. Franco LL. Doenças Tratadas com Plantas Medicinais. $2^{\mathrm{a}}$ ed. Rio de Janeiro (RJ): Vozes; 2003.

14. Corrêa AD, Batista RS, Quintas LEM. Plantas Medicinais: do cultivo à terapêutica. $5^{\mathrm{a}}$ ed. Rio de Janeiro (RI): Vozes; 1998.

15. Pedroso MEM. Crenças relacionadas com a gestação e o puerpério [dissertação]. São Paulo (SP): Escola de Enfermagem. Universidade de São Paulo; 1982.

16. Nakano MAS, Beleza AC, Gomes FA, Mamede FV. O cuidado no "resguardo": as vivências de crenças e tabus por um grupo de puérperas. Rev Bras Enferm 2003; 56(3): 242-7.

17. Cunha PC, Silva AP, Roque OR. Plantas e produtos vegetais em fitoterapia. Lisboa (POR): Fundação Calouste Gulbenkian; 2003.

18. Morgan R. Enciclopédia das ervas e plantas medicinais: Doenças, Aplicações, Descrições e Propriedades. São 
França ISX, et al.

Paulo(SP): Hermus; 1982.

19. Shenkel EP. Cuidados com medicamentos. Florianópolis(SC): UFSC; 1996.

20. Eisenberg D, Davis RB, Ettner SL. Trends in alternative medicine use in the United States, 1990-1997: results of a follow-up national survey. IAMA 1998; 280: 1569-75.

21. Destro MWB, Speranzini MB, Destro C. Estudo da utilização no pré-operatório de medicamentos ou drogas fitoterápicas Que alteram a coagulação sangüínea. Rev Col Bras Cir 2006; 33(2): 107-11.

22. Avila-Pires, FD. Teoria e prática das práticas alternativas. Rev
Saúde Pública 1995; 29(2): |47-51.

23. Organización Mundial de la Salud. Grupo Científico sobre la epidemiología del envejecimiento aplicaciones de la epidemiología al estudio de los ancianos. Genebra (SWT): OMS, 1984.

24. Trovo MM, Silva MJP, Leão ER. Terapias alternativas/ complementares no ensino público e privado: análise do conhecimento dos acadêmicos de enfermagem. Rev Latinoam Enfermagem 2003; 1 I (4): 483-9.

25. Silva MIP, Benko MA. O uso da terapias alternativas por enfermeiros docentes. Rev Bras Enferm 1998; 5(3): 457-68. 